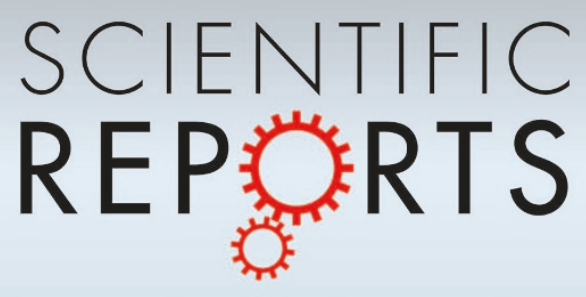

\title{
OPEN A geological perspective on potential future sea-level rise
}

SUBJECT AREAS:

CLIMATE-CHANGE

IMPACTS

PALAEOCEANOGRAPHY

PROJECTION AND PREDICTION

PALAEOCLIMATE

Received

19 June 2013

Accepted

21 November 2013

Published

13 December 2013

Correspondence and requests for materials should be addressed to E.J.R. (eelco.rohling@ anu.edu.au)

\author{
Eelco J. Rohling ${ }^{1,2}$, Ivan D. Haigh ${ }^{2}$, Gavin L. Foster ${ }^{2}$, Andrew P. Roberts' \& Katharine M. Grant ${ }^{1,2}$
}

'Research School of Earth Sciences, The Australian National University, Canberra 0200 Australia, ${ }^{2}$ Ocean and Earth Science, University of Southampton, National Oceanography Centre, Southampton SO 14 3ZH, UK.

During ice-age cycles, continental ice volume kept pace with slow, multi-millennial scale, changes in climate forcing. Today, rapid greenhouse gas (GHG) increases have outpaced ice-volume responses, likely committing us to $>9 \mathrm{~m}$ of long-term sea-level rise (SLR). We portray a context of naturally precedented SLR from geological evidence, for comparison with historical observations and future projections. This context supports SLR of up to $0.9(1.8) \mathrm{m}$ by 2100 and $2.7(5.0) \mathrm{m}$ by 2200 , relative to 2000 , at $68 \%$ (95\%) probability. Historical SLR observations and glaciological assessments track the upper $68 \%$ limit. Hence, modern change is rapid by past interglacial standards but within the range of 'normal' processes. The upper 95\% limit offers a useful low probability/high risk value. Exceedance would require conditions without natural interglacial precedents, such as catastrophic ice-sheet collapse, or activation of major East Antarctic mass loss at sustained $\mathrm{CO}_{2}$ levels above 1000 ppmv.

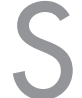
ea-level rise is a certain consequence of global warming. Throughout ice-age cycles of the past million years, sea levels have fluctuated between $\sim 130$ m below and $\sim 10 \mathrm{~m}$ above the present level ${ }^{1-3}$. Melt-back of all ice remaining today would cause about $65 \mathrm{~m}$ of SLR. Modern society is vulnerable to much smaller changes in sea level ${ }^{4}$; some 600 million people currently live within $10 \mathrm{~m}$ of present-day sea level, in an area that generates $10 \%$ of the world's total GDP 5 . An assessment of 136 of the world's largest port cities estimated that, by the 2070s, the population exposed to flooding risk may grow by more than a factor of three in these cities due to the combined effects of SLR, land subsidence, population growth and urbanization, with asset exposure increasing to more than ten times current levels ${ }^{6}$. SLR of up to $2 \mathrm{~m}$ may displace almost $2.5 \%$ of the global population ${ }^{7}$. Understanding potential future SLR therefore is of utmost importance.

A recent expert assessment inferred a $95 \%$ probability range of $0.33-1.32 \mathrm{~m}$ of SLR by 2100 for $3.5^{\circ} \mathrm{C}$ global warming $^{8}$. An earlier estimate, based on current ice dynamical responses ${ }^{9}$, inferred a total SLR of $0.8 \mathrm{~m}$ by 2100 , with an (unlikely) maximum of $2.0 \mathrm{~m}$. The lower estimate relies on two ice-contribution scenarios with realistic accelerations of outlet glacier flow speeds, whereas the high estimate was considered unlikely because it requires an instantaneous jump to high speeds.

Semi-empirical studies have established various relationships between sea level and climate parameters (e.g., temperature, forcing), and have made future projections based on IPCC emission scenarios ${ }^{10-13}$. Such studies typically project total SLR ranges between $\sim 1$ and $2 \mathrm{~m}$ by 2100 . Other methods also suggest high future SLR values. For example, Meehl et $\mathrm{al}^{14}$. modelled SLR values for different emission scenarios (representative concentration pathways, $\mathrm{RCP}^{15}$ ) (Table 1). In terms of rates after 2100, the lowest RCP considered (2.6) gives an SLR rate of $0.15-0.20 \mathrm{~m}$ per century $\left(\mathrm{m} \mathrm{cy}^{-1}\right.$ ) (up to $1.2 \mathrm{~m} \mathrm{cy}^{-1}$ at the extreme of the uncertainty envelope) ${ }^{14}$, while the highest RCP (8.5) gives an SLR rate of $\sim 1 \mathrm{~m} \mathrm{cy}^{-1}\left(\sim 5 \mathrm{~m} \mathrm{cy}^{-1} \text { at the extreme of their uncertainty envelope }\right)^{14}$. Currently observed emission rates are close to RCP8.5 (ref. 16).

Discussions of SLR and rates of SLR rapidly become abstract without sufficient context to gauge the plausibility of implicated processes and ice-retreat rates. We assess changes in the natural, pre-anthropogenic past to offer a perspective of what nature has done before and so might do again. Our assessment is guided by two questions. First: is today's climate system in equilibrium with forcing? Second: what are the natural timescales and rates of change in ice-volume adjustment to a disequilibrium state, relative to a forcing increase? We first assess geological data for (approximate) answers to these questions, and then use the compiled information in a probabilistic evaluation of the natural context to future SLR projections. Because we assess a wide range of SLR rates and adjustment timescales from available geological evidence, we implicitly consider a natural range of forcing types (orbital, major feedbacks) and rates (up to $1.5 \mathrm{~W} \mathrm{~m}^{-2} \mathrm{ky}^{-1}$ of annual mean global forcing, or about $3 \mathrm{~W} \mathrm{~m}^{-2} \mathrm{ky}^{-1}$ of annual mean forcing at high northern latitudes ${ }^{17}$, where ky stands for thousand years). Anthropogenic rates of climate forcing, close to a global mean of $1 \mathrm{~W} \mathrm{~m}^{-2} \mathrm{cy}^{-1}$, are much faster than the natural rates considered. For our forward look we assume 
Table 1 | Recent projections ${ }^{14,15}$ of $\mathrm{CO}_{2}$ levels, global warming, and SLR

\begin{tabular}{|c|c|c|c|c|c|}
\hline RCP & $\mathrm{CO}_{2}$ (ppmv) & Warming by $2100\left({ }^{\circ} \mathrm{C}\right)$ & SLR by $2100(\mathrm{~m})$ & Warming by $2200\left({ }^{\circ} \mathrm{C}\right)$ & SLR by $2200(\mathrm{~m})$ \\
\hline 2.6 & Peak at 440 , Stabilised at 360 & $\sim 1.8$ & 0.25 & $\sim 1.5$ & 0.39 \\
\hline 4.5 & Stabilised at 540 & $\sim 2.6$ & 0.37 & $\sim 3.0$ & 0.71 \\
\hline 8.5 & $2000+$ & $\sim 5$ & 0.56 & $>7$ & 1.53 \\
\hline
\end{tabular}

RCP $=$ Representative Concentration Pathways.

that - at least - the modern forcing by $\mathrm{CO}_{2}$ levels of 392-394 ppmv is maintained (no reduction). Our aim is to portray the plausible longerterm consequences of naturally precedented SLR rates and adjustment timescales. We then use that context to assess whether modern observed responses are exceptional/unique to the industrial period.

\section{Results}

The answer to the first question, whether today's climate system is in equilibrium with forcing, is negative. Anthropogenic climate forcing is more than an order of magnitude faster than climate forcing or major feedbacks at any known time in the Cenozoic ${ }^{18}$. Key climatesystem components, such as deep ocean temperature and ice volume, respond slowly due to their large inertia. Ice-volume contributions to future SLR will therefore reflect delayed responses to GHG emissions, developing climate system feedbacks, and future emissions. The large and fast-growing disequilibrium between accelerated climate forcing and slow/lagging response thus creates a strong potential for rapid sea-level adjustments. The current disequilibrium may be evaluated by comparing present-day conditions with geological data that illustrate the likely climate-system state if it had been given sufficient time to respond completely to the change in forcing.

Some studies have evaluated the natural relationship between climate change and sea-level response $e^{\text {e.g.19,20 }}$, but continuous, high-resolution sea-level records are needed for a sound observation-based assessment. Rohling et $\mathrm{al}^{2}$. presented such a record, and quantified the relationship between sea level and polar temperature ${ }^{21}$ over the last 500,000 years. They assumed a 2:1 ratio between Antarctic and global mean temperature variability (estimates range from 1.2 to 2.5 ; refs. 17,22,23) and their dataset for the last 500,000 years was dominated by climates colder than today. To better extrapolate into warmer states, Foster and Rohling ${ }^{24}$ compiled results from periods both warmer and colder than today, during the past 40 million years (Figure 1). They avoided complications involved in calibrating Antarctic or deep-sea temperature data to global mean temperature, by instead using $\mathrm{CO}_{2}$ reconstructions to compare with sea-level reconstructions. Their dataset includes periods of cooling/ $\mathrm{CO}_{2}$ decrease and warming $/ \mathrm{CO}_{2}$ increase. For $\mathrm{CO}_{2}$ levels below $600 \mathrm{ppmv}$, these trajectories appeared indistinguishable, which instils confidence that the $\mathrm{CO}_{2}$ :sea-level relationship provides useful information about natural longer-term responses expected for anthropogenic $\mathrm{CO}_{2}$ increases.

The inferred $\mathrm{CO}_{2}$ :sea-level relationship is non-linear (Figure 1). Below 350 ppmv, sea level increases almost linearly with increasing $\mathrm{CO}_{2}$. The curve then flattens until $\mathrm{CO}_{2}$ reaches 700 ppmv, above which sea level rises strongly again with $\mathrm{CO}_{2}$ increase. The 'plateau' for $\mathrm{CO}_{2}$ between $\sim 350$ and 700 ppmv, with sea level within a range of $22^{+13} /-12 \mathrm{~m}$ above present, likely represents a climate state in which the (relatively sensitive) ice sheets of Greenland, West Antarctica, and marine-based parts of East Antarctica were severely reduced or eliminated $^{17,20}$. The large East Antarctic ice sheet (EAIS) is more stable, and only contributes significantly to sea-level change when $\mathrm{CO}_{2}$ is above 700 ppmv. This agrees with modelling of $\mathrm{CO}_{2}$ sensitivity of the EAIS, which suggests a $\sim 700$ ppmv threshold ${ }^{25,26}$. Note that the degree of hysteresis in EAIS growth and decay remains debated; $\mathrm{CO}_{2}$ may need to rise above 1000 ppmv before EAIS contributions to SLR become relevant $^{26,27}$.

Annual mean $\mathrm{CO}_{2}$ levels reached 392-394 ppmv in 2011-2012. If this level is maintained, then the sea level: $\mathrm{CO}_{2}$ relationship ${ }^{24}$ suggests a natural longer-term climate state with equilibrium sea level at $24^{+7} /{ }_{-15} \mathrm{~m}$ above the present level (68\% probability). This raises our second question, which concerns the timescales needed for such sea-level adjustments. To answer it, we need information about rates of SLR.

It is less straightforward to use geological data to answer the second question because present-day climate change due to rapid GHG emissions is: (a) unprecedentedly rapid ${ }^{18}$ relative to changes due to orbital forcing and climate system feedbacks ${ }^{17,28}$, and $(b)$ becoming warmer than a normal interglacial ${ }^{29}$. Regardless, geological observations can at least provide a sound natural context for modern trends and future projections. Highly resolved sea-level data, as required to quantify rates of SLR, span the five most recent ice-age cycles ( $\sim 500 \mathrm{ky})$ (refs. 2,30,31).

Information about rates of SLR is most easily obtained from deglaciations, when ice ages terminated and sea level rose by up to $120-130 \mathrm{~m}$ at mean rates of about $1 \mathrm{~m} \mathrm{cy}^{-1}$, but with rapid steps

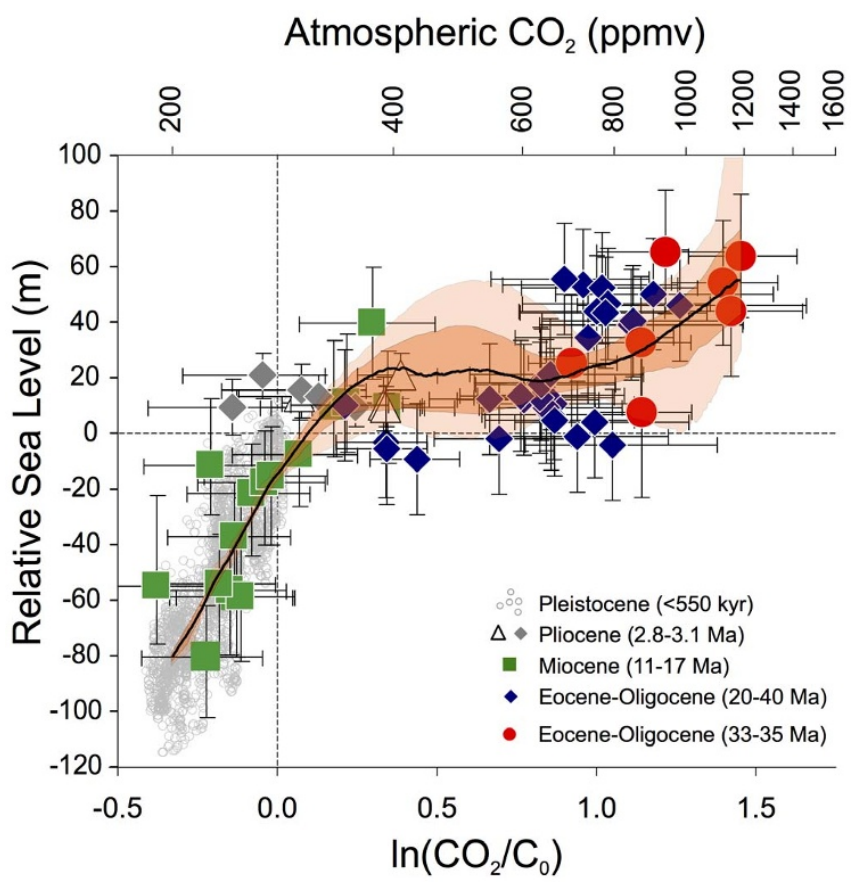

Figure 1 Sea-level versus $\mathrm{CO}_{2}$ concentrations (and the logarithmic radiative forcing influence of $\mathrm{CO}_{2}$ changes ${ }^{17,28}$, expressed by $\ln \left(\mathrm{CO}_{2} / \mathrm{C}_{0}\right)$, where $\mathrm{C}_{0}$ represents the preindustrial $\mathrm{CO}_{2}$ level of 278 ppmv), after ref. 24. Symbols represent reconstructions with uncertainties for different intervals of the past 40 million years. The black line and orange envelopes represent a probabilistic assessment that takes into account full propagation of all uncertainties (black line is the probability maximum; dark orange is the $68 \%$ probability interval; light orange is the $95 \%$ probability interval $)^{24}$. The relationship averages over orbital configurations. Hence, at any given $\mathrm{CO}_{2}$ concentration, periods with 'warmer/colder than average' orbital configurations for the northern hemisphere may have had higher/lower sea level, respectively (e.g., Last Interglacial sea level reached 8-9 $\mathrm{m}$ above Holocene values, although $\mathrm{CO}_{2}$ concentrations were similar). 
bracketed by slower episodes ${ }^{31-37}$. During one of these rapid steps ('meltwater pulse 1a; mwp-1a'), SLR rates reached $4-5 \mathrm{~m} \mathrm{cy}^{-1}$ for several centuries ${ }^{36}$. Rapid steps of $>2 \mathrm{~m} \mathrm{cy}^{-1}$ also occurred during previous deglaciations ${ }^{2,30,31,35}$. Note that past deglacial SLR rates characterise transitions from glacials with 2-3 times the present-day ice volume, to interglacials with ice volumes similar to the present.

Away from deglaciations, data for 75-30 ky ago, when sea level fluctuated between about 60 and $90 \mathrm{~m}$ below the present level, reveal rates of SLR when major Northern Hemisphere ice sheets were consistently present (with fluctuating volume). This is a significantly different state than deglaciations. Grant et $\mathrm{al}^{31}$. provided improved age control and uncertainty propagation relative to earlier quantifications $^{38-40}$, which revealed that all phases of considerable ice-volume reduction had SLR rates of 1-2 $\mathrm{m} \mathrm{cy}^{-1}$ (comparable with mean rates during deglaciations). This suggests that peak rates during deglaciations may reflect special conditions, but that rates of $1-2 \mathrm{~m} \mathrm{cy}^{-1}$ are not exceptional for natural fluctuations. Nevertheless, these rates concern times with much greater ice volume than today, and with intense global climate fluctuations ${ }^{17,28,31,41-44}$.

The most valuable information on rates of SLR comes from periods when global ice volumes were similar to present. The last five glacial cycles contain two interglacials that were up to $2^{\circ} \mathrm{C}$ (ref. 45) warmer than the pre-industrial state, with sea level up to $10 \mathrm{~m}$ higher than today ${ }^{2,3,30,46-48}$. Few data cover the oldest of these, centred at around $404 \mathrm{ky}$ ago, but the Last Interglacial (LIg; 130-115 ky ago $^{48}$ ) has been extensively studied. LIg global temperature was about $1 \pm 0.5^{\circ} \mathrm{C}$ higher than pre-industrial temperature ${ }^{45}$ and sea level peaked 6-9 $\mathrm{m}$ above the present level ${ }^{46-48}$, which implies a $10-15 \%$ ice-volume reduction relative to present. Initial (Red Sea-based) LIg SLR rate estimates of $1.6 \pm 1.0 \mathrm{~m} \mathrm{cy}^{-1}$ lacked direct age control ${ }^{46}$. Subsequent studies proposed 1000-year average $\mathrm{LIg}$ rates of $>$ $0.26 \mathrm{~m} \mathrm{cy}^{-1}$ (ref. 49) and 0.56-0.92 $\mathrm{m} \mathrm{cy}^{-1}$ (ref. 47), which is consistent with a 1000-year smoothed estimate of $0.7 \pm 0.4 \mathrm{~m} \mathrm{cy}^{-1}$ over the -5 to $+5 \mathrm{~m}$ sea-level range based on improved dating of the Red Sea record ${ }^{31}$. Note that such smoothing masks brief intervals with more rapid rise. Data from western Australia suggest a rapid rise within the LIg at $0.6 \mathrm{~m} \mathrm{cy}^{-1}$ (ref. 50). We infer that LIg SLR likely occurred at sustained rates of $\sim 1 \mathrm{~m} \mathrm{cy}^{-1}$ or less.

Here, we capture the (above) compiled geological observations of past rates, and also of timescales, of ice-volume/sea-level adjustment in broadly defined probability distributions (Methods; Figure 2). We then develop a probabilistic assessment of SLR, and use this natural context to discuss historical SLR trends and future projections (Methods, Figure 3).

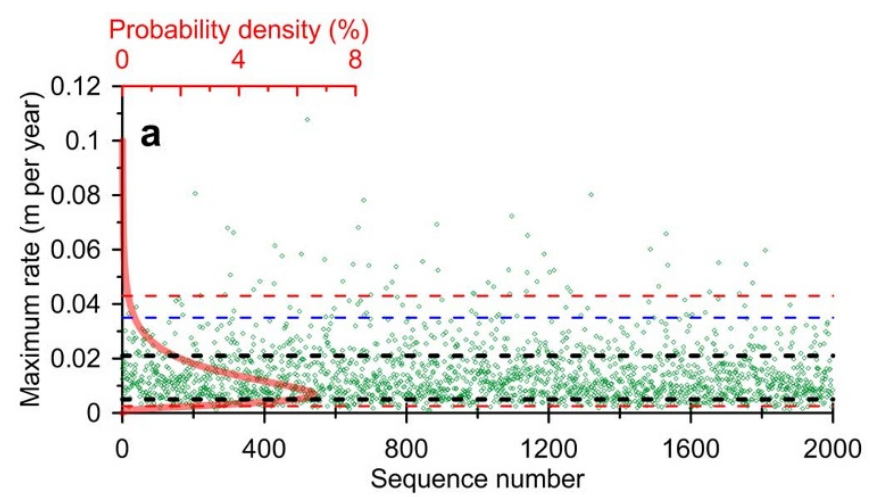

\section{Discussion}

Within the wide parameter ranges considered (Methods; Figure 2), previous high estimates of about 0.8 to $1.3 \mathrm{~m}$ SLR by 2100 refs. 8,9, and historical SLR trends ${ }^{11,51}$, fall near the upper bound of our $68 \%$ probability interval of natural (pre-anthropogenic) change (Figures 3c,d). Semi-empirical SLR projections ${ }^{12}$ (Figure 3c,d) accelerate in high-emission scenarios to high SLR values from about 2050, but in low-emission scenarios remain close to the upper bound of our $68 \%$ probability interval.

The lower half of our $68 \%$ probability interval relates to input parameter values that are close to LIg values (see above). Coincidence of recent observations and projections with the upper bound of our $68 \%$ probability interval therefore suggests that current SLR responses are high by a natural interglacial standard. However, coincidence with the $0.8 \mathrm{~m}$ SLR estimate for 2100 based on icedynamics ${ }^{9}$ suggests that tracking the upper bound of our $68 \%$ probability interval does not require unprecedented processes. Here, we note that this $0.8 \mathrm{~m}$ estimate ${ }^{9}$ is based on extrapolation of well-constrained processes for Greenland to a global context, but that proportionally greater contributions might be possible from Antarctica, where marine grounded channels are not well-defined. We also emphasise that, given the multi-centennial timescales of full adjustment (Methods), $0.8 \mathrm{~m}$ by 2100 represents a transient mean for the current century along a trajectory toward rates of almost $2 \mathrm{~m} \mathrm{cy}^{-1}$ by about 2200 (Figure 3a). LIg data suggest that rapid rates may be sustained at least until SLR reaches +8 to $+10 \mathrm{~m}$ (i.e., until $\sim 2500$ for the upper bound of our $68 \%$ interval; Figure $3 \mathrm{~b}$ ).

SLR in semi-empirical projections for high emission scenarios reaches toward the upper bound of our $90 \%$ interval (Figure 3c,d). This therefore requires development of: (1) ice-loss processes without known precedents in past warm (interglacial) intervals, leading to eventual rates of SLR of almost $3.5 \mathrm{~m} \mathrm{cy}^{-1}$ (Figure 3a), and (2) unexpected increases to modern outlet-glacier flow regimes, relative to the assessment of Pfeffer et $\mathrm{al}^{9}$. This does not mean that such scenarios cannot occur; we only infer from the natural context that such potential developments would be unique to the anthropogenic era.

Given the need for long-term planning in coastal defence, we consider a 'worst case' outlook from our natural perspective. The upper bound of our $95 \%$ probability envelope (i.e., the $97.5^{\text {th }}$ percentile) implies a $2.5 \%$ chance of $>1.8 \mathrm{~m}$ SLR by 2100 and $>5.0 \mathrm{~m}$ by 2200 , relative to 2000 (Figure 3 ). This 2100 value closely approaches the (unlikely) maximum value suggested by Pfeffer et $\mathrm{al}^{9}$. (Figure 3c). However, this trajectory requires that SLR rates develop toward an eventual value of $4.3 \mathrm{~m} \mathrm{cy}^{-1}$, roughly similar to

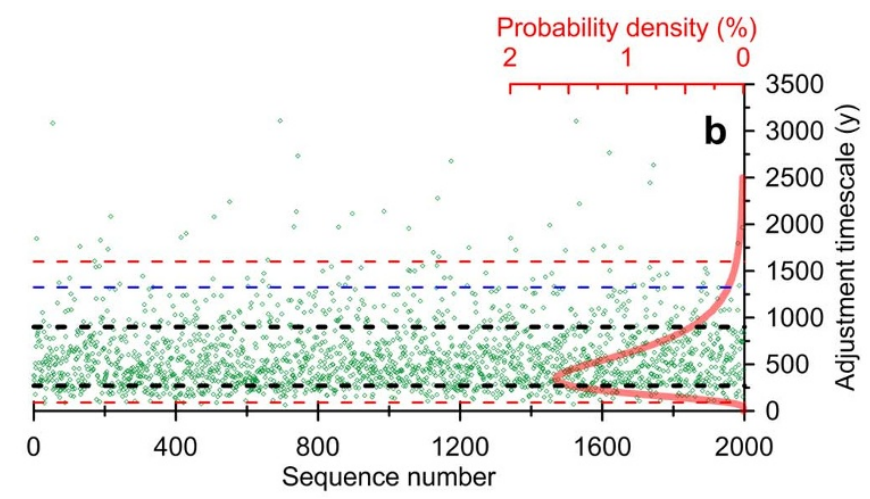

Figure $2 \mid$ Probability distributions (red) for: (a). maximum rates of SLR (shown in $\mathrm{m}^{-1}$, as used in the calculations); and (b). adjustment timescales (in y), as discussed in the text. The green dots indicate the 2000 random samplings of the probability distributions for our probabilistic assessment of natural sea-level change based on equations $1-3$. Dashed red lines indicate the $2.5^{\text {th }}$ and $97.5^{\text {th }}$ percentiles that delimit $95 \%$ probability intervals; dashed blue lines indicate $95^{\text {th }}$ percentiles that give the upper bound of the $90 \%$ probability intervals (to avoid clutter the lower bound has been omitted); and dashed black lines indicate $16^{\text {th }}$ and $84^{\text {th }}$ percentiles that delimit the $68 \%$ probability intervals. 

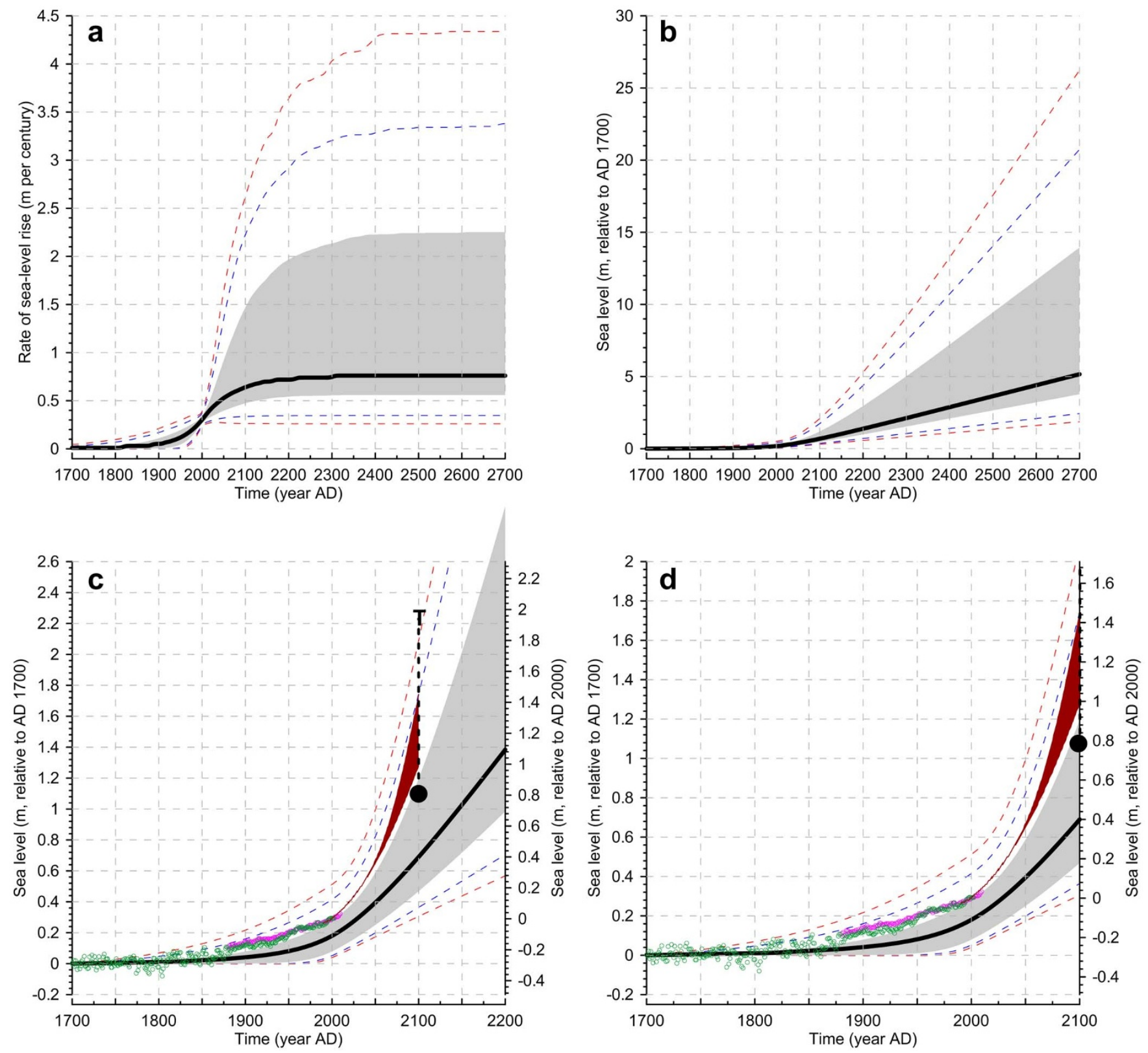

Figure $3 \mid$ Probabilistic assessment of natural sea-level change based on equations 1-3. The heavy line is the probability maximum (peak of the probability distribution), the grey envelope marks the $68 \%$ probability interval, and the dashed blue (red) lines mark the $90 \%$ (95\%) probability intervals, respectively. (a). Rates of SLR relative to 1700 , in $\mathrm{m} \mathrm{cy}^{-1}$ (i.e., $100 \times$ result from equation 1). (b). SLR after equation (2). (c). Zoomed-in portion of (b), ending at 2200. The brown wedge is the range of semi-empirical projections by Vermeer and Rahmstorf ${ }^{12}$, the heavy dot outlines the most-likely projection by Pfeffer et $\mathrm{al}^{9}$., and the heavy dashed black line represents the full range of SLR estimates of Pfeffer et al ${ }^{9}$. Historical sea-level reconstructions of Jevrejeva et $\mathrm{al}^{11}$. (green dots) and Church and White ${ }^{51}$ (magenta dots) are also shown. (d). As (c), but zoomed in on 1700-2100.

mwp-1a (ref. 36) (Figure 3a), even though today's global ice volume is only about a third of that at the onset of the last deglaciation. Most of the extra ice during glacial times existed in North America and northwestern Eurasia, where it extended to relatively low latitudes $\left(40-50^{\circ} \mathrm{N}\right)$. These ice sheets were highly sensitive to climate change, as witnessed by the fact that they existed during ice ages and were almost entirely absent during interglacials. Both the size and sensitivity of these glacial ice masses would have been conducive to high deglacial rates of SLR. Starting from present-day conditions, rates such as those of mwp-1a would require unprecedented ice-loss mechanisms, such as collapse of a major ice sheet (e.g., the largely marine-based West Antarctic Ice Sheet). Alternatively, such rates might develop with a large increase in the amount of 'vulnerable' ice, by activation of major EAIS retreat. From the natural perspective, however, the latter only seems to become relevant under extreme GHG forcing, with long-term $\mathrm{CO}_{2}$ above $\sim 1000 \mathrm{ppmv}$ or so (see Figure 1, and discussion above). Without invoking such exceptional conditions or catastrophic events, our assessment supports the notion $^{9}$ that $\sim 2 \mathrm{~m}$ of SLR by 2100 represents a useful upper limit. Improved (less smoothed, and globally documented) SLR rate estimates from past interglacials are needed to further refine this value, and especially the risk of massive ice-sheet collapse.

Early historical SLR data are scattered because there are few long tide-gauge records, but from $\sim 1880$ the record is well defined (Figure $3 \mathrm{c}, \mathrm{d}$ ). While the data generally coincide with the upper half of our $68 \%$ probability interval for naturally precedented changes, the observations contain some superimposed multi-decadal variability, for which there are several explanations. Since the 1950s, 


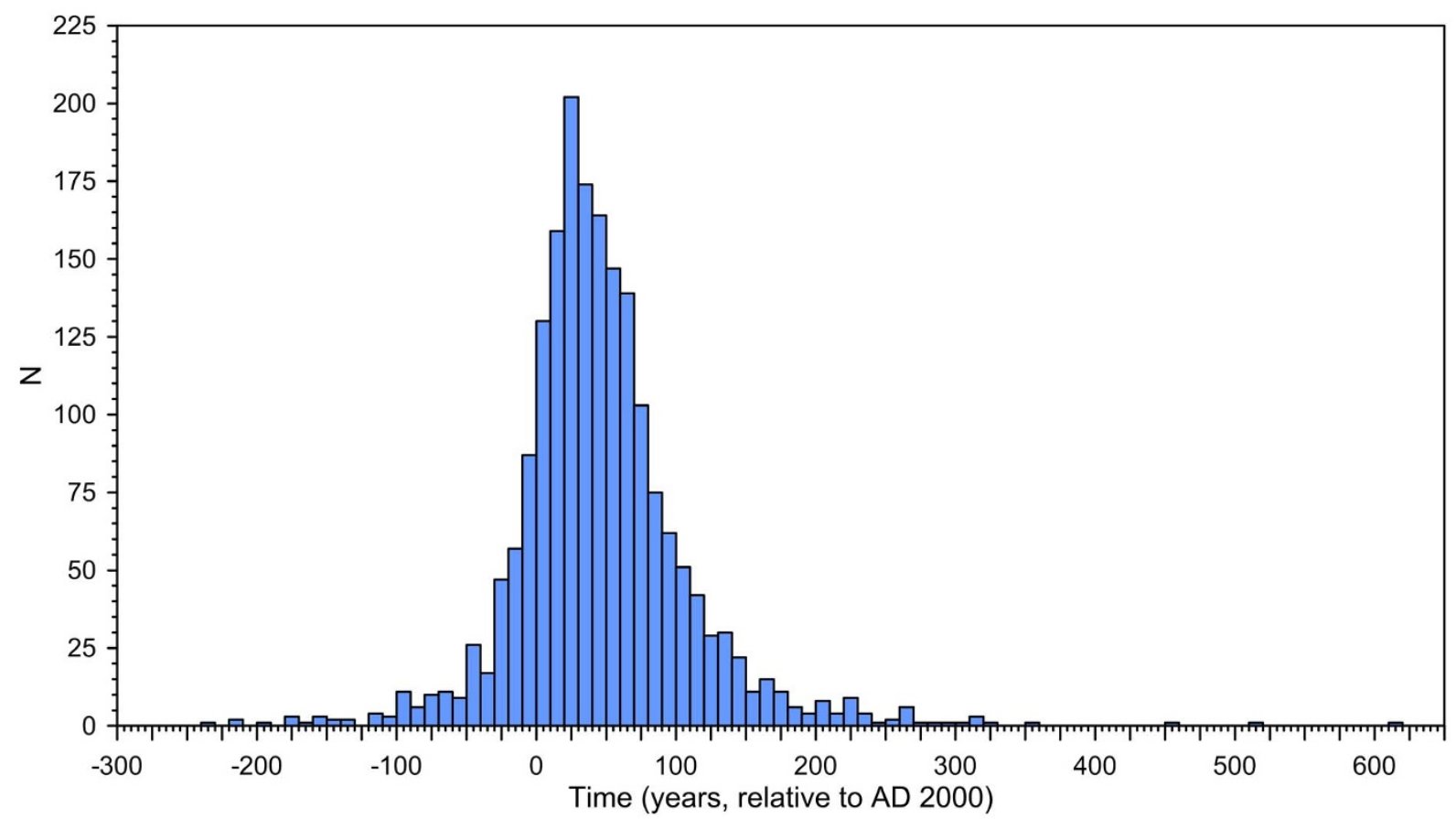

Figure $4 \mid$ Histogram of $t_{i n f}$ the relative age of the inflection from concave to convex in our 2000 sigmoidal (logistic) SLR rate reconstructions.

increased water storage on land behind man-made dams has led to reduced $\mathrm{SLR}^{52}$, and increased volcanic eruptions in the latter half of the $20^{\text {th }}$ century increased atmospheric albedo and reduced ocean heat content, limiting thermal expansion ${ }^{53}$. In addition, relatively rapid initial SLR may have arisen because proportionally more heat remained in the ocean - where it rapidly caused thermal expansion while less heat was used for (slower) ice-sheet retreat. Since 1950, this balance may have shifted to reducing contributions from thermal expansion and accelerating ice-volume contributions. The latter interpretation is consistent with observations of recent increasing mass loss from major ice sheets ${ }^{54-56}$. Our evaluations are not designed to reproduce such multidecadal variability, but in a sensitivity test we have included representative annual, interannual, and multidecadal variability of differing amplitudes into our 2000 iterations of SLR rates (Supplementary Information Figures S1,S2). This results in only marginal widening of the probability intervals relative to Figure 3, and our conclusions are not affected.

Overall, the most important point from our assessment is that SLR since 1700 has been consistent (within uncertainties) with expectations from geologically documented responses to climate-system disequilibria. Thus, no matter how special anthropogenic climate forcing may be in terms of magnitude and rate of increase, the observed sea-level response to anthropogenic forcing has so far remained close to the range of expectations based on well-known natural precedents.

Continued monitoring of SLR, and comparison with the natural context outlined here, may be used to identify if and when sea-level response becomes 'special' (i.e., unprecedented during geological interglacials). For example, the higher emissions projections of Vermeer and Rahmstorf ${ }^{12}$ imply a shift toward such 'special' responses from $\sim 2050$. Until such time, however, comparison of SLR observations with our results indicates that future SLR projections can rely with confidence on testing and validation of physical models against well-known examples from the recent geological past.

\section{Methods}

The disequilibrium between rapidly increased anthropogenic climate forcing and slow ice-volume responses amounts to many metres of SLR at current atmospheric $\mathrm{CO}_{2}$ levels, and may not change significantly with increasing $\mathrm{CO}_{2}$ to $700 \mathrm{ppmv}$ (Figure 1) ${ }^{24}$. Temperature adjustments to emission scenarios within that range follow a sigmoidal pattern with time, accelerating and then decelerating, with adjustment timescales between 150 years for low-emission scenarios and 400 years for highemission scenarios ${ }^{15}$. We infer that the present disequilibrium is already sufficient to cause build-up toward major ice-sheet responses, and that further warming will occur over similar timescales as the developing ice-sheet responses, so that increased forcing would cause (rapid) shifts toward extremes of the parameter ranges considered here (high ultimate SLR rates and rapid adjustment timescales). The median global radiative forcing projections for high-emission RCPs is $\sim 12 \mathrm{~W} \mathrm{~m}^{-2}$ (ref. 15). For deglaciations, this was $8-10 \mathrm{~W} \mathrm{~m}^{-2}$ (refs. 17,28). We infer that the long-term consequences of high-emission RCPs may be suitably gauged from the SLR adjustment rates and timescales of deglaciations, if we assume that such consequences would develop via naturally precedented processes (e.g., because the response becomes ratelimited). Similar to a previous study ${ }^{57}$, we consider that the long-term consequences of low- to middle-emission RCPs may be gauged using LIg responses. We proceed on this basis to formulate our 'natural context'.

The processes that govern mass-loss from ice sheets build up gradually because of dynamical spin-up or due to slow increases in early melting until ice-sheet heighttemperature feedbacks lead to rapid acceleration ${ }^{9,54,58,59}$. Hence, our assessment allows rates of SLR to gradually build, and then accelerate, before settling at the maximum achievable rate for the mechanisms involved ( $\alpha$ in our analysis below, in $\mathrm{m} \mathrm{y}^{-1}$ ). We approximate this using a logistic function of the form:

$$
\frac{d \Delta_{s}}{d t}=\frac{\alpha}{1+\beta e^{-\frac{t}{\gamma} c}}
$$

Here $\gamma$ is the timescale over which the rate increases from zero to its peak value (in y). $\beta$ is discussed below. The dimensionless scaling constant $C$ is empirically set so that $\gamma$ equals the period over which $d^{2} \Delta_{S} / d t^{2}$ exceeds $1 \%$ of its maximum value. $C$ is independent of $\alpha, \beta$, and $\gamma$; it depends merely on the cutoff criterion used for $d^{2} \Delta_{S} / d t^{2}$. Our consistently applied criterion implies that $C=12$ in all iterations. The timing of the central inflection in $d \Delta_{S} / d t$, the switch-over from accelerating to decelerating rates of SLR (with the constraint that at AD2000, the SLR rate is $3 \pm 1 \mathrm{~mm} \mathrm{y}^{-1}$, see below), is $t_{\text {inf }}=\gamma \ln (\beta) / C$. A histogram for all 2000 iterations (Figure 4) suggests that $t_{\text {inf }}$ falls within a window of $\sim 300$ years. For comparison, modeled developments from zero to maximum SLR rates from Greenland, over a wide range of climate forcing scenarios, suggest inflection-point timings within a 200-year window (2100-2300) (analysis based on Figure 3b of ref. 59), which is qualitatively similar to our inference.

Integration of equation (1) gives $\Delta_{S}$ (i.e., SLR) in $\mathrm{m}$ relative to pre-industrial times (AD1700):

$$
\Delta_{s}=\int_{0}^{t}\left[\frac{\alpha}{1+\beta e^{-\frac{t}{\tau} c}}\right] d t
$$

All calculations are performed in $\mathrm{m} \mathrm{y}^{-1}$, but we present results in $\mathrm{m} \mathrm{cy}^{-1}$ for comparison with previous studies. The dimensionless parameter $\beta$ is set so that the rate of SLR at AD2000 amounts to $3 \mathrm{~mm} \mathrm{y}^{-1}$ (i.e., $0.003 \mathrm{~m} \mathrm{y}^{-1}$ or $0.3 \mathrm{~m} \mathrm{cy}^{-1}$ ), with a Gaussian uncertainty distribution over a range of $\pm 1 \mathrm{~mm} \mathrm{y}^{-1}$ (represented by rnd $(0.001)$ in equation 3), based on observations from satellite altimetry for 1993 to present ${ }^{51}$ : 


$$
\beta=\frac{\alpha}{0.003 \pm \operatorname{rnd}(0.001)}-1
$$

Geological data constrain a broad probability distribution for $\alpha$. Rates must be $>0 \mathrm{~m}$ $\mathrm{cy}^{-1}$ for SLR to occur. The probability peak may be expected at around the rate of LIg SLR above present levels of $0.56-0.92 \mathrm{~m} \mathrm{cy}^{-1}$ or $0.7 \pm 0.4 \mathrm{~m} \mathrm{cy}^{-1}$ (refs. 31,47,50) (i.e., $<1.1 \mathrm{~m} \mathrm{cy}^{-1}$ ), with the caveat that 1000 -year averaged LIg estimates may mask shorter episodes with higher values. Mwp-1a, with rates of SLR up to $\sim 5 \mathrm{~m} \mathrm{cy}^{-1}$ (ref. 36), provides a real-world example of naturally occurring extreme rates. Accordingly, we formulate a simple lognormal distribution, so that $\alpha>0 \mathrm{~m} \mathrm{cy}^{-1}$, with $50 \%$ of possibilities for $\alpha \leq 1.1 \mathrm{~m} \mathrm{cy}^{-1}$, and with $99 \%$ of $\alpha \leq 5.0 \mathrm{~m} \mathrm{cy}^{-1}$ (red curve in Figure 2a).

Similar conditions exist for the adjustment timescale $(\gamma)$. The lower constraint must be $\gamma>0$ y. Where detailed records exist, rates of SLR tracked rates of polar temperature change within a few centuries, while sea-levels tracked a new temperature stasis within 2 to 7 centuries $^{31}$. However, response times of about a millennium or more may not be excluded ${ }^{59,60}$. For example, mass-loss rates of the Greenland icesheet develop toward maxima over about 750 years in a recent model ${ }^{59}$. Hence, we define a lognormal distribution so that $\gamma>0 \mathrm{y}$, with $50 \%$ of possibilities for $\gamma \leq$ 500 y, and with $99 \%$ of $\gamma \leq 2000$ y (red curve in Figure 2b).

Equations 1-3 are solved in a probabilistic assessment. In a Monte-Carlo style approach, we performed 2000 independent random samplings of the $\alpha$ and $\gamma$ distributions (Figure 2), and of $\beta$ (equation 3 ). Next, we evaluated per annual time-step the probability distribution defined by the 2000 solutions ( $95 \%$ probability limits using the $2.5^{\text {th }}$ and $97.5^{\text {th }}$ percentiles, $90 \%$ limits with the $5^{\text {th }}$ and $95^{\text {th }}$ percentiles, and $68 \%$ limits using the $16^{\text {th }}$ and $84^{\text {th }}$ percentiles). Results are shown in $\mathrm{m} \mathrm{cy}^{-1}$ in Figure 3a, and those for SLR in m (eq. 2) in Figure 3b-d.

1. Rohling, E. J. et al. Magnitudes of sea-level lowstands of the past 500,000 years Nature 394, 162-165 (1998).

2. Rohling, E. J. et al. Antarctic temperature and global sea level closely coupled over the past five glacial cycles. Nature Geosci. 2, 500-504 (2009).

3. Raymo, M. E. \& Mitrovica, J. X. Collapse of polar ice sheets during the stage 11 interglacial. Nature 483, 453-456 (2012).

4. Pugh, D. T. Changing Sea Levels. Effects of Tides, Weather and Climate. 280 pp. (Cambridge University Press, 2004).

5. McGranahan, G., Balk, D. \& Anderson, B. The rising tide: assessing the risks of climate change and human settlements in low elevation coastal zones. Environ. Urbanisation 19, 17-37 (2007).

6. Hallegatte, S., Green, C., Nicholls, R. J. \& Corfee-Morlot, J. Future flood losses in major coastal cities. Nature Clim. Change doi:10.1038/NCLIMATE1979.

7. Nicholls, R. J. et al. Sea-level rise and its possible impacts given a 'beyond $4{ }^{\circ} \mathrm{C}$ world' in the twenty-first century. Phil. Trans. Roy. Soc. A 13, 161-181 (2011).

8. Bamber, J. L. \& Aspinall, W. P. An expert judgement assessment of future sea level rise from the ice sheets. Nature Clim. Change 3, 424-427 (2013)

9. Pfeffer, W. T., Harper, J. T. \& O’Neel, S. Kinematic constraints on glacier contributions to 21st-century sea-level rise. Science 321, 1340-1343 (2008).

10. Rahmstorf, S. A semi-empirical approach to projecting future sea-level rise. Science 315, 368-370 (2007).

11. Jevrejeva, S., Moore, J. C., Grinsted, A. \& Woodworth, P. L. Recent global sea level acceleration started over 200 years ago? Geophys. Res. Lett. 35, L08715 doi:10.1029/2008GL033611 (2008).

12. Vermeer, M. \& Rahmstorf, S. Global sea level linked to global temperature. Proc. Natl. Acad. Sci. USA 106, 21527-21532 (2009).

13. Kemp, A. C. Climate related sea-level variations over the past two millennia. Proc. Natl. Acad. Sci. USA 108, 11017-11022 (2011).

14. Meehl, G. A. et al. Relative outcomes of climate change mitigation related to global temperature versus sea-level rise. Nature Clim. Change 2, 576-580 (2012).

15. Meinshausen, M. et al. The RCP greenhouse gas concentrations and their extension from 1765 to 2300. Climatic Change 109, 213-241 (2011).

16. Peters, G. P. et al. The challenge to keep global warming below $2^{\circ} \mathrm{C}$. Nature Clim. Change 3, 4-6 (2013).

17. Rohling, E. J., Medina-Elizalde, M., Shepherd, J. G., Siddall, M. \& Stanford, J. D. Sea surface and high-latitude temperature sensitivity to radiative forcing of climate over several glacial cycles. J. Clim. 25, 1635-1656 (2012).

18. Hönisch, B. et al. The geological record of ocean acidification. Science 335 1058-1063 (2012)

19. Alley, R. B., Clark, P. U., Huybrechts, P. \& Joughin, I. Ice-sheet and sea-level changes. Science 310, 456-460 (2005).

20. De Boer, B., Van de Wal, R. S. W., Bintanja, R., Lourens, L. J. \& Tuenter, E. Cenozoic global ice-volume and temperature simulations with 1-D ice-sheet models forced by benthic $\delta^{18} \mathrm{O}$ records. Annals Glaciol. 51, 23-33 (2010).

21. Jouzel, J. et al. Orbital and millennial Antarctic climate variability over the past 800,000 years. Science 317, 793-797 (2007)

22. Masson-Delmotte, V. et al. Past and future polar amplification of climate change: climate model intercomparisons and ice-core constraints. Clim. Dyn. 26, 513-529 (2006).

23. PALAEOSENS Project Members. Making sense of palaeoclimate sensitivity. Nature 491, 683-691 (2012).

24. Foster, G. L. \& Rohling, E. J. The relationship between sea level and climate forcing by $\mathrm{CO}_{2}$ on geological timescales. Proc. Natl. Acad. Sci. USA 110, 1209-1214 (2013).
25. DeConto, R. M. \& Pollard, D. Rapid Cenozoic glaciation of Antarctica induced by declining atmospheric $\mathrm{CO}_{2}$. Nature 421, 245-249 (2003).

26. Pollard, D. \& DeConto, R. M. Hysteresis in Cenozoic Antarctic ice-sheet variations. Global Planet. Change 45, 9-21 (2005).

27. Hill, D. J., Haywood, A. M., Hindmarsh, R. C. A. \& Valdes, P. J. Characterising ice sheets during the Pliocene: evidence from data and models. In Williams, M., Haywood, A. M., Gregory, J. \& Schmidt, D. (eds.).Deep Time Perspectives on Climate Change pp. 517-538 (The Geological Society of London, London, 2007).

28. Köhler, P. et al. What caused Earth's temperature variations during the last 800,000 years? Data-based evidence on radiative forcing and constraints on climate sensitivity. Quat. Sci. Rev. 29, 129-145 (2010).

29. Marcott, S. A., Shakun, J. D., Clark, P. U. \& Mix, A. C. A Reconstruction of regional and global temperature for the past 11,300 years. Science 339, 1198-1201 (2013).

30. Rohling, E. J. et al. Comparison between Holocene and Marine Isotope Stage-11 sea-level histories. Earth Planet. Sci. Lett. 291, 97-105 (2010).

31. Grant, K. M. et al. Rapid coupling between ice volume and polar temperature over the past 150 kyr. Nature 491, 744-747 (2012).

32. Lambeck, K., Yokoyama, Y. \& Purcell, T. Into and out of the Last Glacial Maximum: sea-level change during Oxygen Isotope Stages 3 and 2. Quat. Sci. Rev. 21, 343-360 (2002).

33. Stanford, J. D. et al. Timing of meltwater pulse la and climate responses to meltwater injections. Paleoceanography, 21, PA4103, doi: 10.1029/ 2006PA001340 (2006).

34. Stanford, J. D. et al. Sea-level probability for the last deglaciation: a statistical analysis of far-field records. Global Planet. Change 79, 193-203 (2011).

35. Siddall, M., Bard, E., Rohling, E. J. \& Hemleben, C. Sea-level reversal during Termination II. Geology 34, 817-820 (2006).

36. Deschamps, P. et al. Ice-sheet collapse and sea-level rise at the Bølling warming 14,600 years ago. Nature 483, 559-564 (2012).

37. Carlson, A. E. \& Clark, P. U. Ice sheet sources of sea level rise and freshwater discharge during the last deglaciation. Rev. Geophys. 50, RG4007, doi:10.1029/ 2011RG000371 (2012).

38. Siddall, M. et al. Sea-level fluctuations during the last glacial cycle. Nature 423, 853-858 (2003)

39. Arz, H. W. et al. Dominant Northern Hemisphere climate control over millennialscale glacial sea-level variability. Quat. Sci. Rev. 26, 312-321 (2007).

40. Rohling, E. J., Marsh, R., Wells, N. C., Siddall, M. \& Edwards, N. Similar meltwater contributions to glacial sea-level variability from Antarctic and northern ice sheets. Nature 430, 1016-1021 (2004).

41. Dansgaard, W. et al. Evidence for general instability of past climate from a $250-\mathrm{kyr}$ ice-core record. Nature 364, 218-220 (1993).

42. Grootes, P. M., Stuiver, M., White, J. W. C., Johnsen, S. J. \& Jouzel, J. Comparison of oxygen isotope records from the GISP2 and GRIP Greenland ice cores. Nature 366, 552-554 (1993).

43. Rohling, E. J., Mayewski, P. A. \& Challenor, P. On the timing and mechanism of millennial-scale climate variability during the last glacial cycle. Clim. Dyn. 20, 257-267 (2003)

44. EPICA Community Members. One-to-one coupling of glacial climate variability in Greenland and Antarctica. Nature 444, 195-198 (2006).

45. Hansen, J., Sato, M., Russell, G. \& Kharecha, P. Climate sensitivity, sea level, and atmospheric $\mathrm{CO}_{2}$. Phil. Trans. R. Soc. A, in press (2013).

46. Rohling, E. J. et al. High rates of sea-level rise during the last interglacial period. Nature Geosci. 1, 38-42 (2008).

47. Kopp, R. E., Simons, F. J., Mitrovica, J. X., Maloof, A. C. \& Oppenheimer, M. Probabilistic assessment of sea level during the last interglacial stage. Nature 462, 863-868 (2009).

48. Dutton, A. \& Lambeck, K. Ice volume and sea level during the last interglacial. Science 337, 216-219 (2012).

49. Thompson, W. G., Curran, H. A., Wilson, M. A. \& White, B. Sea-level oscillations during the last interglacial highstand recorded by Bahamas corals. Nature Geosci. 4, 684-687 (2011).

50. O'Leary, M. J. et al. Ice sheet collapse following a prolonged period of stable sea level during the last interglacial. Nature Geosci. 6, 796-800 (2013).

51. Church, J. A. \& White, N. J. Sea-level rise from the late $19^{\text {th }}$ to the early $21^{\text {st }}$ Century. Surv. Geophys. 32, 585-602 (2011).

52. Chao, B. F., Wu, Y. H. \& Li, Y. S. Impact of artificial reservoir water impoundment on global sea level. Science 320, 212-214 (2008).

53. Church, J. A., White, N. \& Arblaster, J. Significant decadal-scale impact of volcanic eruptions on sea level and ocean heat content. Nature 438, 74-77 (2005).

54. Rignot, E., Velicogna, I., Van Den Broeke, M. R., Monaghan, A. \& Lenaerts, J. Acceleration of the contribution of the Greenland and Antarctic ice sheets to sea level rise. Geophys. Res. Lett. 38, L05503, doi:10.1029/2011GL046583 (2011).

55. Cazenave, A. et al. Sea level budget over 2003-2008: a reevaluation from GRACE space gravimetry, satellite altimetry and Argo. Global Planet. Change 65, 83-88 (2009).

56. Shepherd, A. et al. A reconciled estimate of ice-sheet mass balance. Science 338, 1183-1189 (2012).

57. Levermann, A. et al. The multimillennial sea-level commitment of global warming. Proc. Natl. Acad. Sci. USA, doi: 10.1073/pnas.1219414110 (2013)

58. Rignot, E. \& Kanagaratnam, P. Changes in the velocity structure of the Greenland Ice sheet. Science 311, 986-990 (2006). 
59. Robinson, A., Calov, R. \& Ganopolski, A. Multistability and critical thresholds of the Greenland ice sheet. Nature Clim. Change 2, 429-432 (2012).

60. Gregory, J. M., Huybrechts, P. \& Raper, S. C. B. Threatened loss of the Greenland ice-sheet. Nature 428, 616 (2004).

\section{Acknowledgments}

This paper contributes to UK-NERC consortium iGlass (NE/I009906/1) and 2012 Australian Laureate Fellowship FL120100050. We thank David Heslop for checking the methods, and Tom Cronin for helpful comments and suggestions.

\section{Author contributions}

E.J.R. led the analyses and writing of the manuscript. All authors added through discussions and reviews of the study, especially A.P.R. and K.M.G. over the past few years of our Red Sea sea-level collaboration. G.L.F. provided a deep-time geological perspective and added Figure 1. I.D.H. added focus on modern implications and assisted with the statistical assessment.

\section{Additional information}

Supplementary information accompanies this paper at http://www.nature.com/ scientificreports

Competing financial interests: The authors declare no competing financial interests.

How to cite this article: Rohling, E.J., Haigh, I.D., Foster, G.L., Roberts, A.P. \& Grant, K.M. A geological perspective on potential future sea-level rise. Sci. Rep. 3, 3461; DOI:10.1038/ srep03461 (2013).

This work is licensed under a Creative Commons Attribution 3.0 Unported license. To view a copy of this license, visit http://creativecommons.org/licenses/by/3.0 